\title{
The effect of embedment on a foundation subjected to vertical vibration - a field study
}

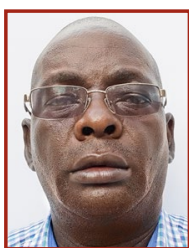

DR SILIPIUS MBAWALA is a lecturer in the Department of Civil Engineering at the Dar es Salaam Institute of Technology (DIT), working in the discipline of Geotechnical Engineering. He holds an Advance Diploma in Civil Engineering from Dar es Salaam Technical College (DTC), and BSC (Hons), MSc and PhD degrees from the University of Pretoria. His field of interest includes geotechnical site characterisation and analytical and numerical modelling of machine foundations.

\section{Contact details:}

Department of Civil Engineering, Dar es Salaam Institute of Technology PO Box 2958, Dar es Salaam, Tanzania

T: +255 754446 537, E: mbawallla@yahoo.com

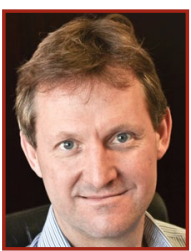

RROF GERHARD HEYMANN (Pr Eng, MSAICE) is Professor in the Department of Civil Engineering at the University of Pretoria. He holds BEng, BEng (Hons) and MEng degrees from the University of Pretoria, and a PhD from the University of Surrey. He has been involved with teaching and research in geotechnical engineering for many years. His field of interest includes the characterisation of

soil behaviour and its application in geotechnical engineering.

\section{Contact details:}

Department of Civil Engineering, University of Pretoria

Pretoria 0002, South Africa

T: +2712 420 3627, E: gerhard.heymann@up.ac.za

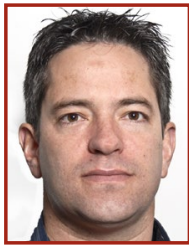

PROF CHRIS ROTH (Pr Eng, FSAICE) is Associate Professor in Civil Engineering at the University of Pretoria, working in the discipline of structural engineering. He started his career in consulting engineering before joining the University of Pretoria, and is the current chairman of SANS Technical Committee 98/Subcommittee 1 on Basis of Design and Actions (including Earthquake Design). He obtained a BEng degree in civil engineering at the University of Stellenbosch, and an MS and PhD at Cornell University. His interests are in structural reliability and structural analysis.

\section{Contact details.}

Department of Civil Engineering, University of Pretoria

Pretoria 0002, South Africa

T: +27 12 420 2185, E: chris.roth@up.ac.za

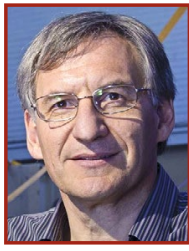

PROF STEPHAN HEYNS is Professor and Director of the Centre for Asset Integrity Management

(C-AIM) at the University of Pretoria. C-AlM focuses on asset structural integrity and covers aspects of the asset life cycle - from structural analysis and structural testing, through data acquisitioning, condition monitoring, diagnostics, prognostics and maintenance management decision-making His research focuses on machine and structural health monitoring using vibration-based condition monitoring, new vibration measurement techniques including optical measurement techniques, as well as various aspects of the broader physical asset integrity management problem.

Contact details:

Department of Mechanical and Aeronautical Engineering

University of Pretoria

Pretoria 0002, South Africa

T: +2712420 2432, E: stephan.heyns@up.ac.za

\section{S J Mbawala, G Heymann, C P Roth, P S Heyns}

Design of machine foundations requires the prediction of the dynamic response of the foundation system at the frequencies of interest. The response is typically quantified in terms of a number of parameters that include the displacement, the dynamic stiffness, the resonant frequency, the amplitude at the resonant frequency and the natural frequency. The objective of this study was to investigate the vertical dynamic response of an embedded foundation experimentally. It was found that embedment increases the stiffness, damping and natural frequency of a foundation system, reduces the displacement and resonant amplitude, but that embedment has very little effect on the resonant frequency.

\section{INTRODUCTION}

Although most machine foundations are partially or fully embedded, there exists little information about the effect of embedment on foundation responses. Nevertheless, it is known that embedment increases the stiffness of a foundation system and reduces the displacement amplitude at resonance. However, the question still remains whether there are additional benefits in fully embedding foundations.

Some researchers report that embedment increases resonant frequency (Novak \& Beredugo 1972; Gupta 1972; Novak 1974), while others believe that embedment causes an insignificant change in the resonant frequency of the foundation system (Chae 1971; Lin \& Jennings 1984; Inukai \& Imazawa 1992). Furthermore, researchers sometimes use resonant frequency and natural frequency interchangeably. The resonant frequency is defined as the forcing frequency at which the peak amplitude occurs. This depends on the propagated waves radiating from the footing, driving forces and boundaries of the system. A resonant frequency exists only if the damping ratio is less than 0.707 (Chopra 2007; Doebelin 1998). The natural frequency is the frequency at which the system will oscillate without being altered by outside forces, and is therefore a property of the system only. Very little work has been done to investigate the effect of embedment on the natural frequency of a foundation system. In addition, contradictory conclusions have been made among researchers with regard to the effect of embedment on the resonant frequency. The design of machine foundations requires the proper prediction of displacement, particularly at the resonant frequency, the dynamic stiffness and the natural frequency. This field study aims at investigating the effects of embedment on these parameters.

\section{EMBEDDED FOUNDATIONS}

The effects of embedment on the dynamic responses of foundations have been studied by various researchers. These studies have suggested that embedment increases the stiffness of the foundation system and reduces the displacement amplitude at resonance (Lysmer \& Kuhlemeyer 1969; Novak 1970; Chae 1971; Novak \& Beredugo 1972; Gupta 1972; Novak 1974; Novak et al 1978; Gazetas 1983; Lin \& Jennings 1984; Gazetas \& Stokoe 1991; Inukai \& Imazawa 1992). The resonant amplitude is the peak amplitude in the frequency response function. It has been suggested by some researchers that embedment increases the resonant frequency of the foundation (Novak \& Beredugo 1972; Gupta 1972). In contrast, other researchers have reported that embedment causes little or no increase of resonant frequency (Chae 1971; Inukai \& Imazawa 1992). Chae (1971) argued that embedment will not cause the resonant frequency to change, because the system mass increases as a result of the surcharge and this will balance the increase in stiffness due to the embedment. Novak (1970) noted that the response of an embedded foundation could be substantially affected by the nature of the contact between the footing and the surrounding soil.

These seemingly contradictory conclusions with regard to the effect of embedment on resonant frequency may be due to how 
the interface between the footing and the adjacent soil is treated. Clearly there is little consensus regarding the effect of embedment on the resonant frequency, and in addition little work has been done to study the effect of embedment on the natural frequency. Therefore, in this study, experiments were conducted to determine the effect of embedment on the behaviour of a footing subjected to vertical vibration.

There are several methods that can be used to describe the effect of foundation embedment. Chae (1971) introduced a dimensionless quantity known as the amplitude reduction coefficient to express the response of an embedded footing under dynamic loading, while Novak and Beredugo (1972) used the resonant amplitude ratio. The resonant amplitude ratio, or amplitude reduction coefficient, is the ratio of the peak amplitude for an embedded footing to the peak amplitude for zero embedment, as shown in Equation 1.

$R_{a}=\frac{U_{\max }}{U_{0 \max }}$

where $U_{\max }$ is the maximum displacement amplitude for a given embedment, and $U_{0 \max }$ is the maximum displacement amplitude for zero embedment. The geometry of an embedded footing is described by the embedment factor (Chae 1971), while Novak and Beredugo (1972) describe the same quantity as the embedment ratio $(\delta)$ given by Equation 2 :

$\delta=\frac{D_{f}}{r_{o}}$

where $D_{f}$ is the embedment depth (as shown in Figure 1) and $r_{o}$ is the radius or equivalent radius of the footing. For a square footing, $r_{o}$ is half the width of the footing, while for a circular footing, $r_{o}$ is the radius of the footing. The effect of embedment on the resonant frequency is expressed in terms of the resonant frequency ratio as:

$R_{f}=\frac{f_{d}}{f_{o}}$

where $f_{o}$ is the resonant frequency of the foundation system with zero embedment and $f_{d}$ is the resonant frequency of the foundation system with an embedment $D_{f}$.

In the same manner, a new dimensionless quantity known as the natural frequency ratio $N_{f}$ is introduced to express the effect of embedment on the natural frequency of foundation systems. The natural frequency ratio $N_{f}$ is the ratio of the natural frequency for an embedded footing to the natural frequency for zero embedment (Equation 4):

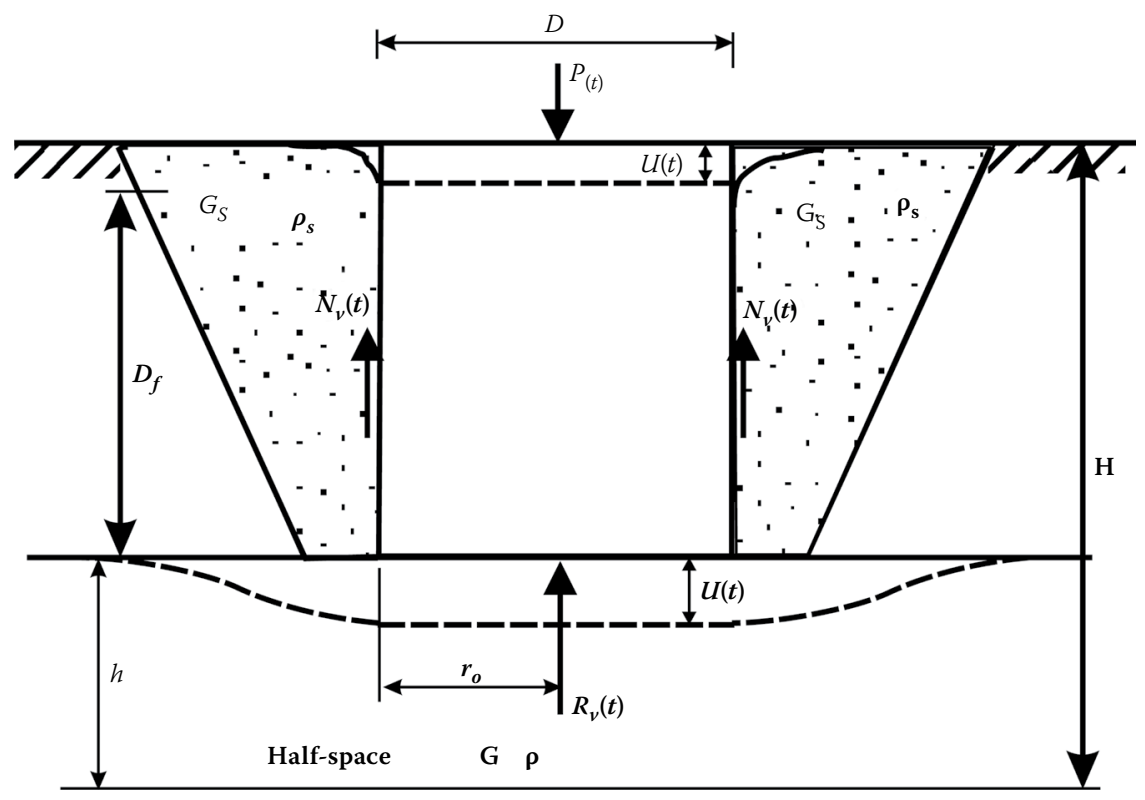

Figure 1: Mathematical model for embedded footing

$N_{f}=\frac{f_{D}}{f_{D_{o}}}$

(4)

where $f_{D}$ is the natural frequency of the foundation system with embedment, and $f_{D_{o}}$ is the natural frequency of the foundation system with zero embedment.

\section{EXPERIMENTAL WORK}

Measurements were made to characterise the behaviour of an embedded footing at the experimental farm of the University of Pretoria. Full details of the experimental work are given in Mbawala (2015). The underlying material was residual andesite, and the general soil profile may be described as silty clay mixed with gravels. The small strain shear stiffness of the soil $(G)$ was measured using the continuous surface wave test (Heymann 2007) and on average was found to be $100 \mathrm{MPa}$ to a depth of $8 \mathrm{~m}$.

A concrete footing with plan dimensions $1200 \mathrm{~mm} \times 1200 \mathrm{~mm}$ and $1240 \mathrm{~mm}$ depth was cast in place as shown in Figure 2(a). The excavation was backfilled and compacted in layers of approximately $150 \mathrm{~mm}$. The fully embedded foundation was left for 12 months to ensure good contact between the surface of the footing and the soil, as shown in Figure 2(b). After 12 months a series of vibration tests were conducted at different levels of embedment. At each excavation stage, the mass density of the layers was measured using the nuclear density method. Foundation embedment depths of $930 \mathrm{~mm}$, $620 \mathrm{~mm}, 310 \mathrm{~mm}$ and $0 \mathrm{~mm}$ are shown in Figures 2(c), 2(d), 2(e) and 2(f) respectively.

A servo-hydraulic shaker was used to excite the footing by applying a harmonic

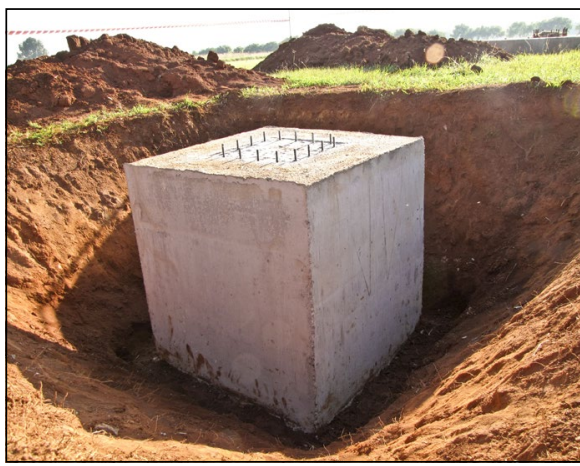

Figure 2(a): Footing (1 $200 \mathrm{~mm} \times 1200 \mathrm{~mm} \times$ $1240 \mathrm{~mm}$ )

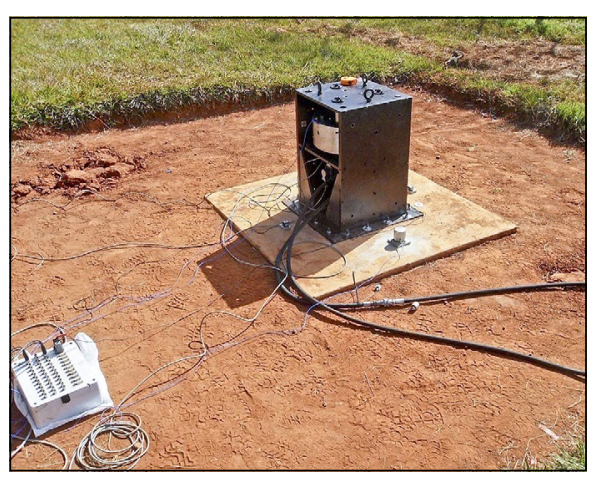

Figure 2(b): Full embedment (1 $240 \mathrm{~mm}$ )

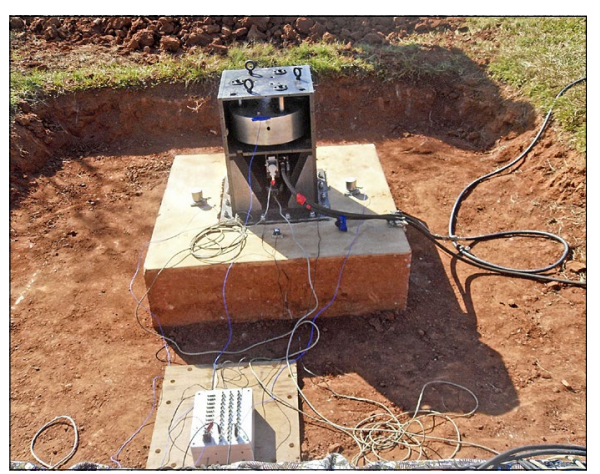

Figure 2(c): $930 \mathrm{~mm}$ embedment 


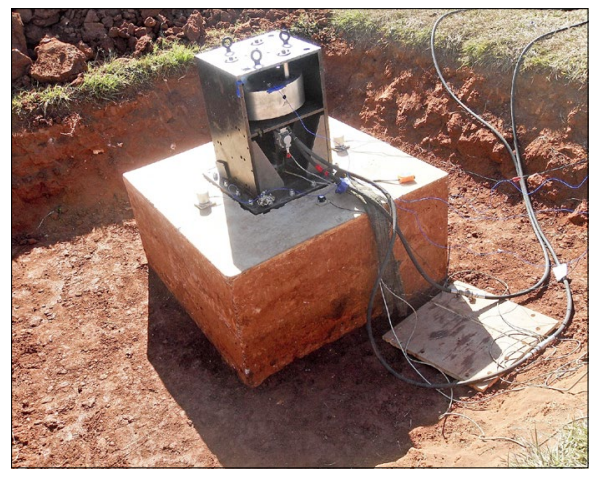

Figure 2(d): $620 \mathrm{~mm}$ embedment

vertical force at frequencies ranging from $10 \mathrm{~Hz}$ to $100 \mathrm{~Hz}$. The foundation system was excited for a few seconds at each forcing frequency to ensure that steady state conditions were reached before recording the output. The vertical dynamic response of the foundation system was measured with two $1 \mathrm{~g}$ accelerometers placed on top of the footing, $200 \mathrm{~mm}$ from the edge of the shaker, as shown in Figure 2(c). The force applied by the shaker at each forcing frequency was measured using a load cell mounted inside the shaker, as shown in Figure 3 . The force amplitude was constant at each frequency but, as shown in Figure 3, it varied at different frequencies. This was due to limitations in the behaviour of the servo-hydraulic system.

The evaluation of impedance functions assumes that the footing is rigid and remains in contact with the soil at all times. Therefore, the displacement of the footing is assumed to be equal to the displacement of the soil surface beneath the footing. Under this condition, the footing may be simplified as a system with a single degree of freedom

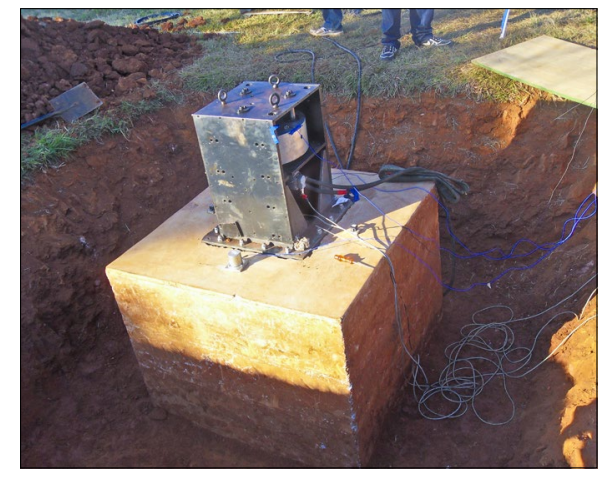

Figure 2(e): $310 \mathrm{~mm}$ embedment

that has a spring, mass and damper. Because the vertical excitation of the foundation system is harmonic, the vertical dynamic displacement response is also harmonic. Therefore, the displacement amplitudes may be calculated from the acceleration data as follows:

$U=\frac{\ddot{U}}{-\omega^{2}}$

where $\ddot{U}$ is the acceleration amplitude and $\omega$ is the angular velocity.

The vertical impedance functions of the foundation system for different embedment depths were obtained by calculating the fast Fourier transform (FFT) for the input and output data. For each excitation frequency, the dynamic impedance functions were calculated using Equation 6, which is the ratio of the applied vertical complex harmonic forces $P(t)$ to the resulting steady state complex displacement response $U(t) . K_{v}$ is the dynamic stiffness of the soil and foundation system, which is frequency-dependent. The frequency dependence is due to the stiffness and inertia of the

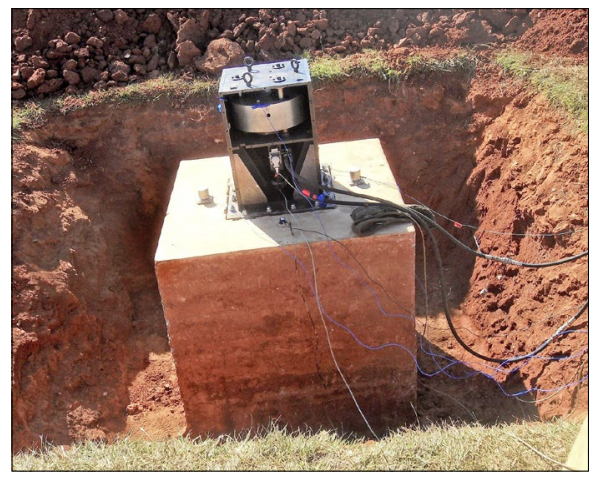

\section{Figure 2(f): $0 \mathrm{~mm}$ embedment}

supporting soil which attributes only to the influence that the frequency exerts on inertia because the soil is frequency-independent.

$K_{v}(\omega)=\frac{P(t)}{U(t)}$

\section{RESULTS AND DISCUSSIONS}

The parameters that are important when designing a machine foundation are the displacement amplitude, stiffness, resonant frequency and natural frequency of the machine foundation system. In this section, the results obtained from the field measurements are presented. The dimensionless values of the resonant amplitude ratio, resonant frequency ratio and natural frequency ratio are also presented.

\section{Displacement amplitude}

Figure 4 shows the measured vertical amplitude response for the different embedment depths. The vertical displacement amplitudes decrease as the embedment increases. The experimental results show two peaks - the first peak is at about $38 \mathrm{~Hz}$ and a second

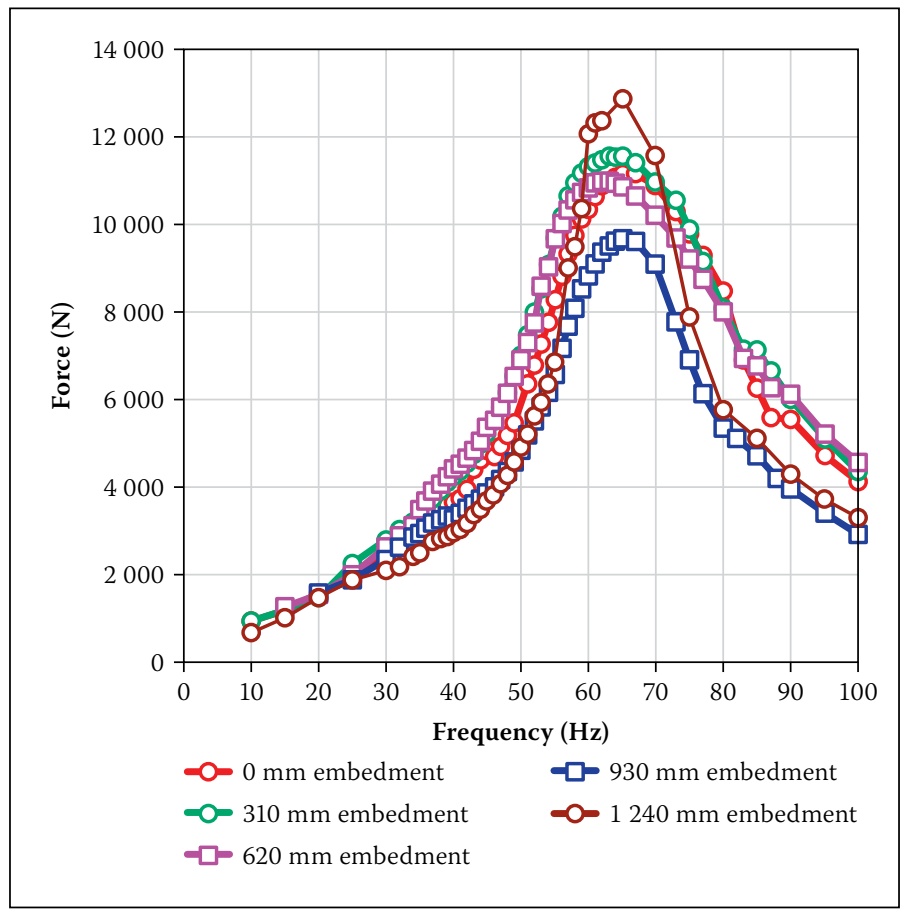

Figure 3: Force measured by the shaker

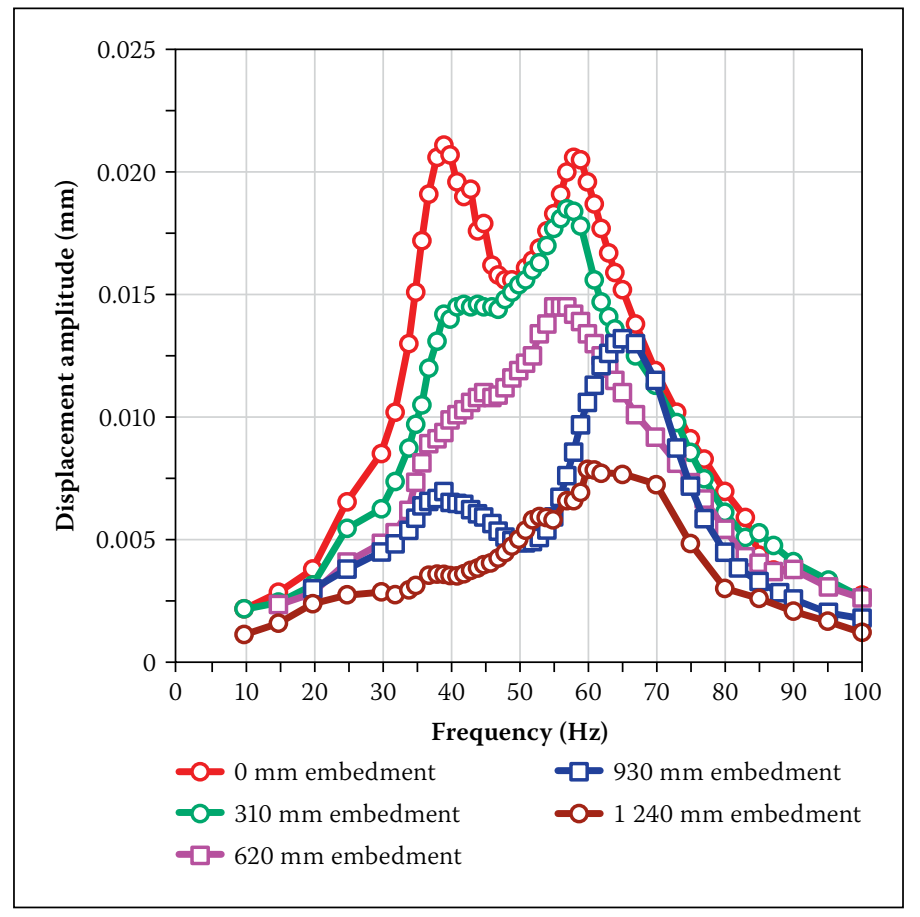

Figure 4: Measured displacement 


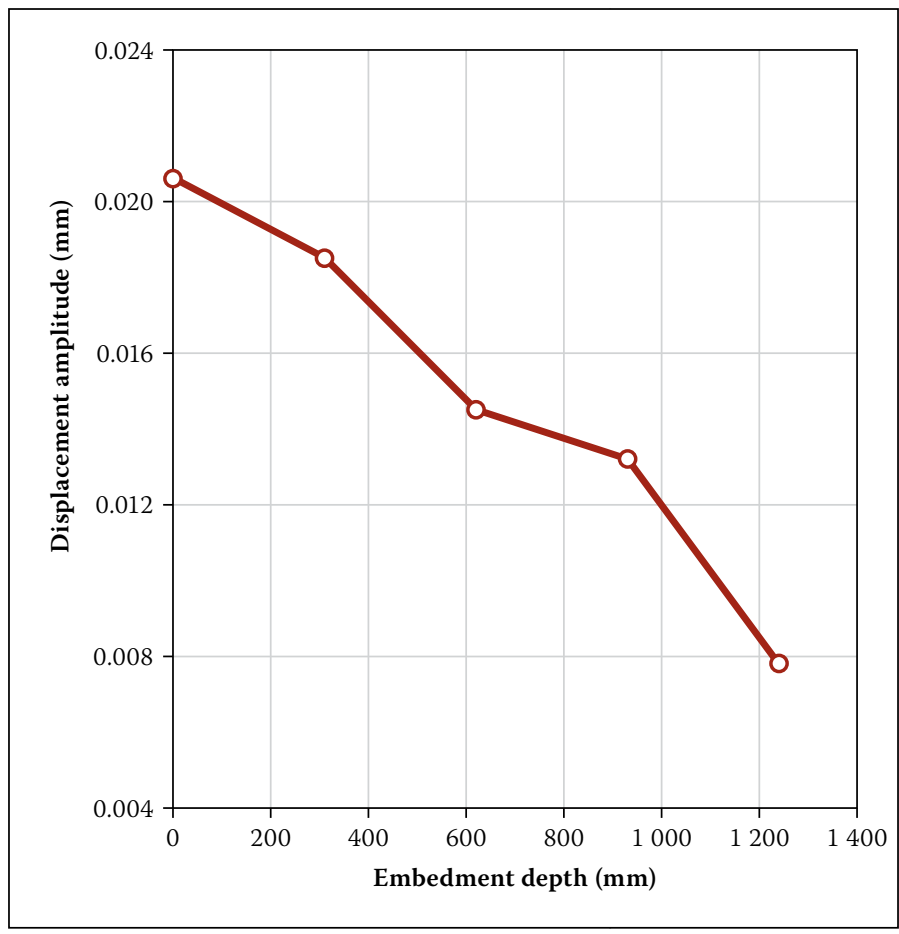

Figure 5: Displacement at peak

peak at about $60 \mathrm{~Hz}$. The first peak is more pronounced at smaller embedment depths compared with greater embedment depths. At low frequencies of about $10 \mathrm{~Hz}$ and at a frequency of approximately $80 \mathrm{~Hz}$, the observed displacement amplitudes show little dependence on embedment depth. Figure 5 shows the plot of displacement at the peak versus embedment depth. It clearly shows that, as embedment increases, the displacement at the peak amplitude decreases.

\section{Resonant amplitude}

The measured displacement was normalised by the applied force to obtain the

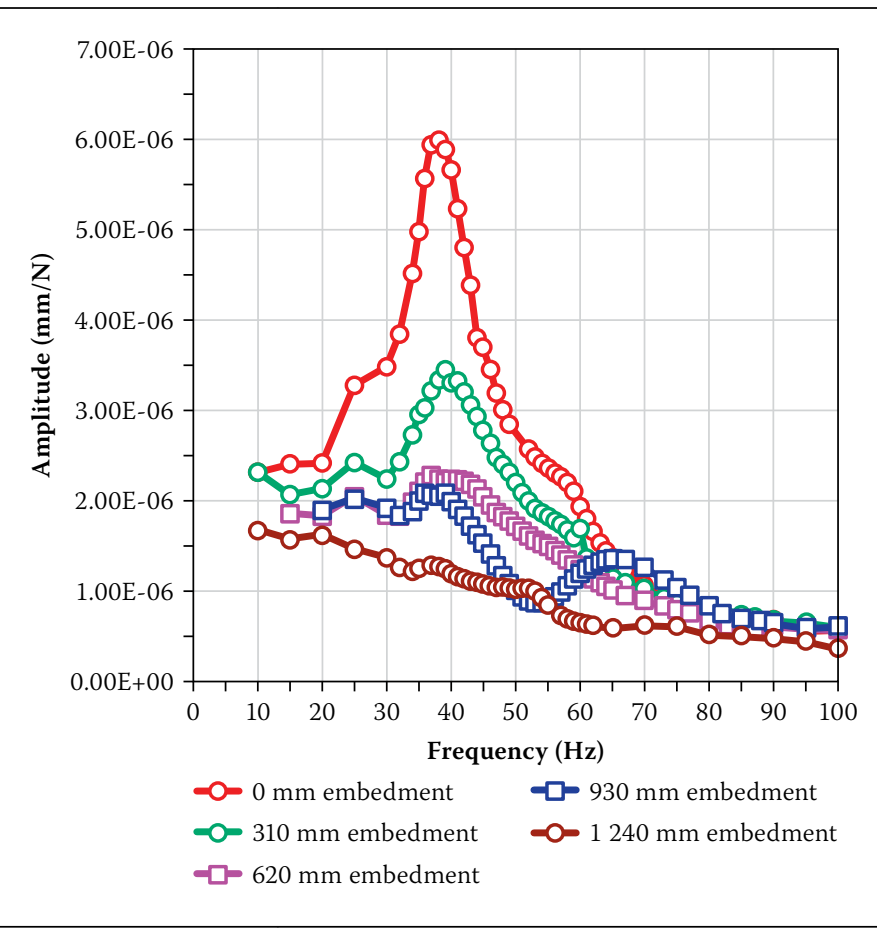

Figure 6: Frequency response function

frequency response function (FRF) as shown in Figure 6. The normalised vertical amplitudes decrease as the embedment increases. The resonant frequency may be observed at about $38 \mathrm{~Hz}$, the frequency at which the peak-normalised amplitude occurred. The experimental data results show a second minor peak at about $60 \mathrm{~Hz}$, which is more pronounced at smaller embedment depths than at greater embedment depths. This coincides with the frequency where the applied harmonic force is a maximum (Figure 3). At frequencies above approximately $80 \mathrm{~Hz}$, the observed amplitudes show little dependence on embedment depth.
Figure 7 shows the peak normalised amplitude for different embedment depths.

The resonant amplitude ratio obtained experimentally is shown in Figure 8. From the figure it is clear that the resonant amplitude ratio decreases as embedment increases. It also shows that the rate of reduction of the resonant amplitude ratio is high at low values of the embedment ratio. This suggests that even small levels of embedment can significantly reduce the maximum vibration amplitude. For instance, in the footing investigated, an embedment of one quarter of the total depth reduced the displacement amplitude by more than

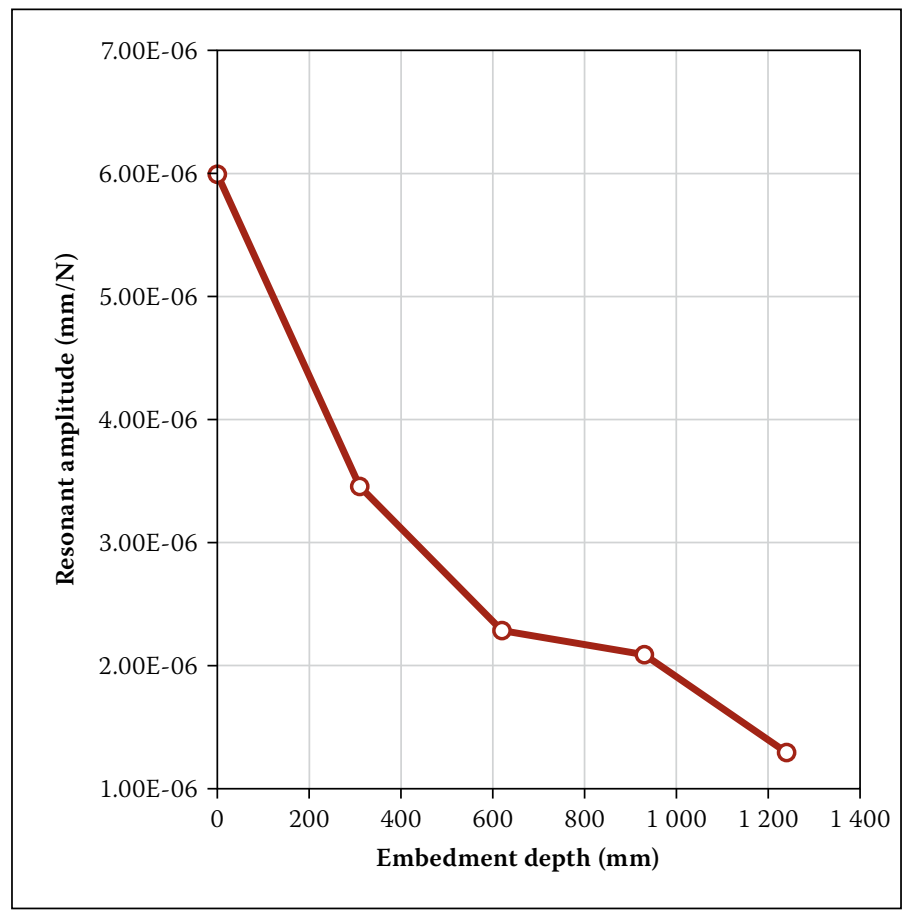

Figure 7: Resonant amplitude

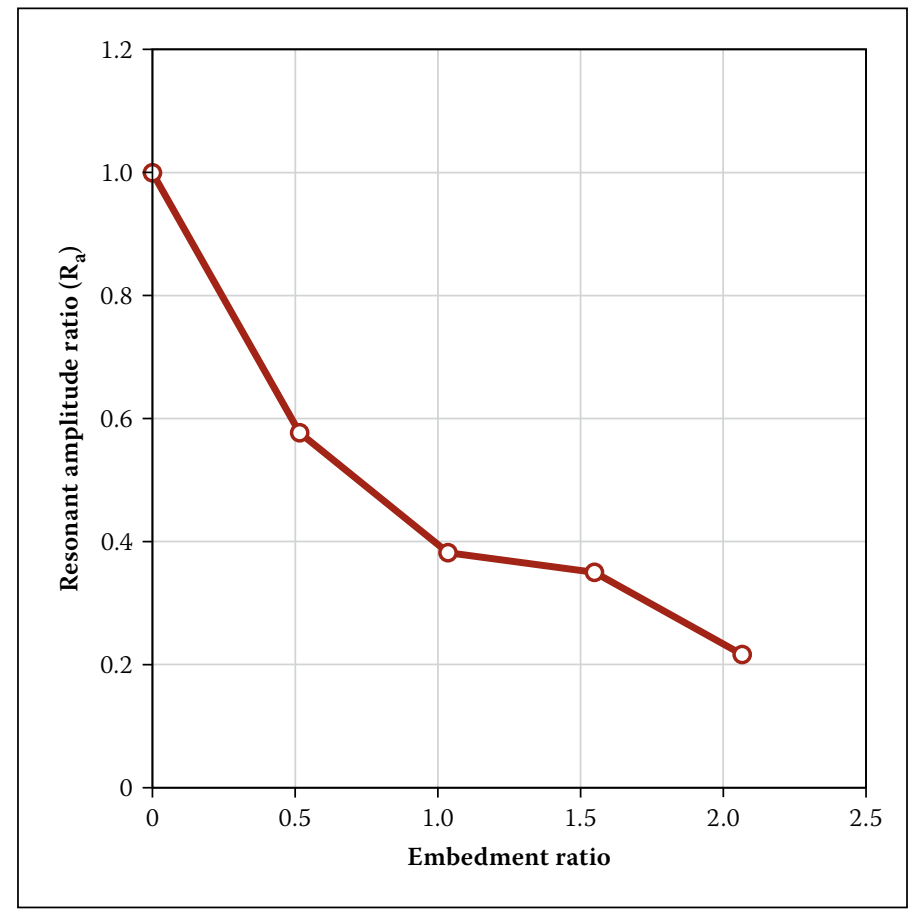

Figure 8: Resonant amplitude ratio 


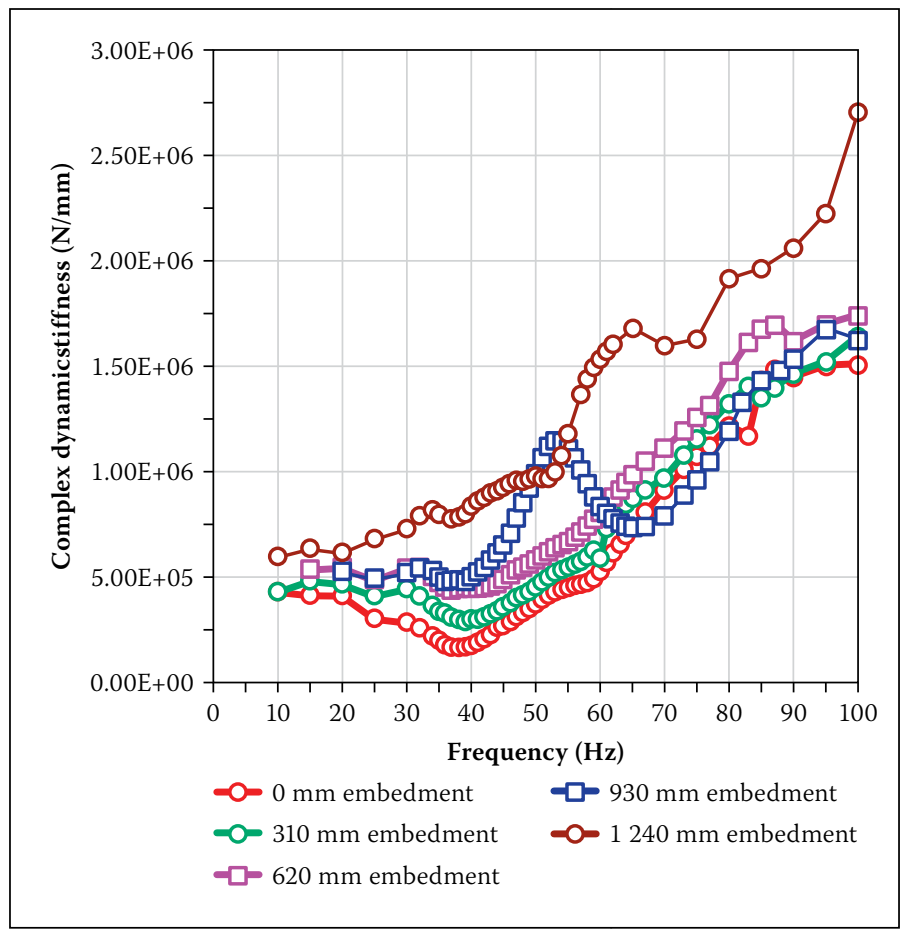

Figure 9: Complex dynamic stiffness

$40 \%$. The results also indicate that the rate of reduction becomes smaller at greater embedment depths. At full embedment, the measured reduction in amplitude was approximately $78 \%$.

\section{Complex dynamic stiffness}

The complex dynamic stiffness obtained from the experimental data, for different levels of embedment, is shown in Figure 9. The complex dynamic stiffness increases as the embedment increases, but the effect of embedment is small at low frequencies. The complex dynamic stiffness is nearly constant up to about $20 \mathrm{~Hz}$. For low levels

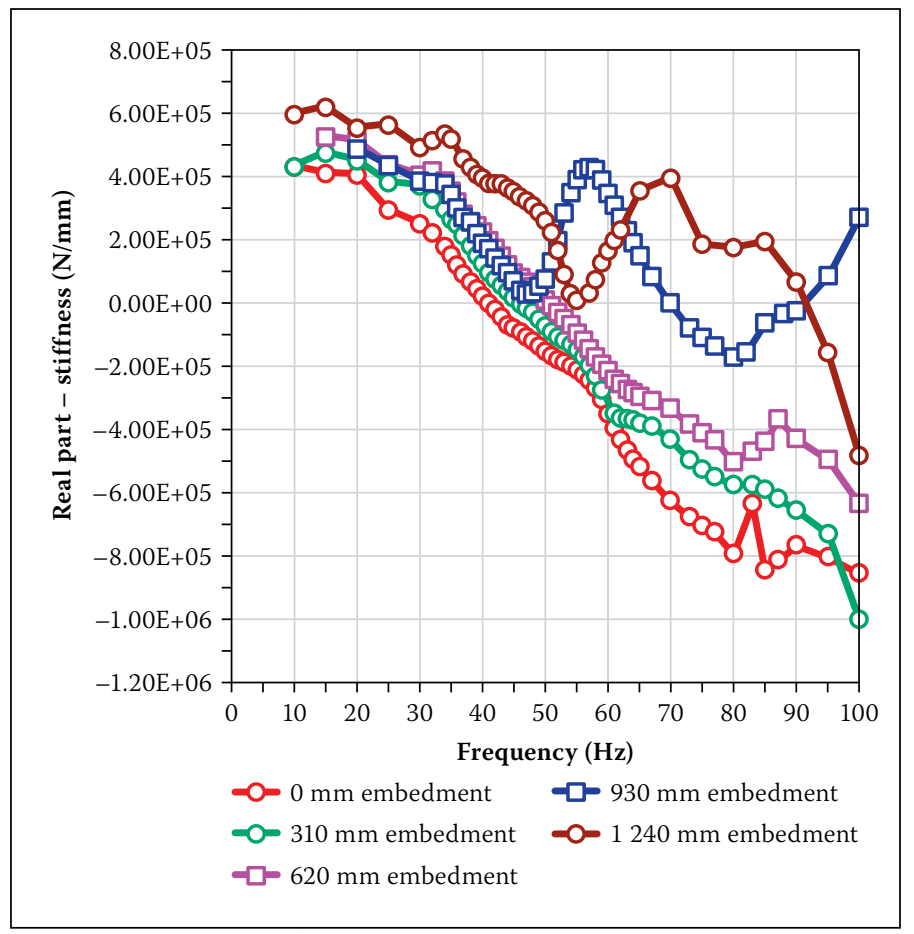

Figure 10: Real part of complex dynamic stiffness

of embedment it reaches a minimum at approximately $38 \mathrm{~Hz}$ and increases at frequencies above $38 \mathrm{~Hz}$. The resonant frequency may be estimated from the plot of complex dynamic stiffness as the frequency where the complex dynamic stiffness is a minimum.

Figure 10 shows a plot of the real part of the complex dynamic stiffness versus forcing frequency. The results show that the real part of complex dynamic stiffness increases as the embedment increases. The natural frequency of the foundation system occurs at the frequency where the real part of the complex dynamic stiffness crosses zero. It may be seen from Figure 10 that the natural frequency of the foundation system increased as the embedment increased.

The imaginary part of the complex dynamic stiffness indicates the level of damping of the foundation system. For foundation systems where the magnitude of the vibration amplitude is low, damping is mainly as a result of radiation damping. The plot of the imaginary part of the complex dynamic stiffness is shown in Figure 11. The results show that the imaginary part of the complex dynamic stiffness increases as the embedment increases, showing that embedment increases damping.

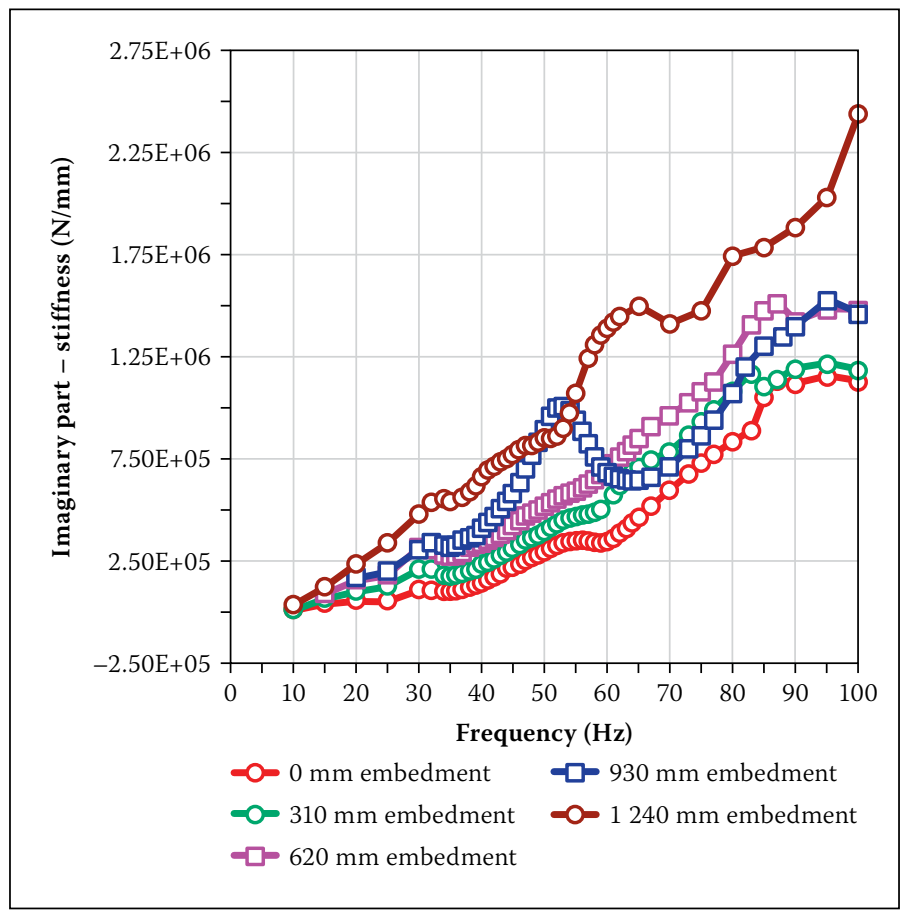

Figure 11: Imaginary part of complex dynamic stiffness

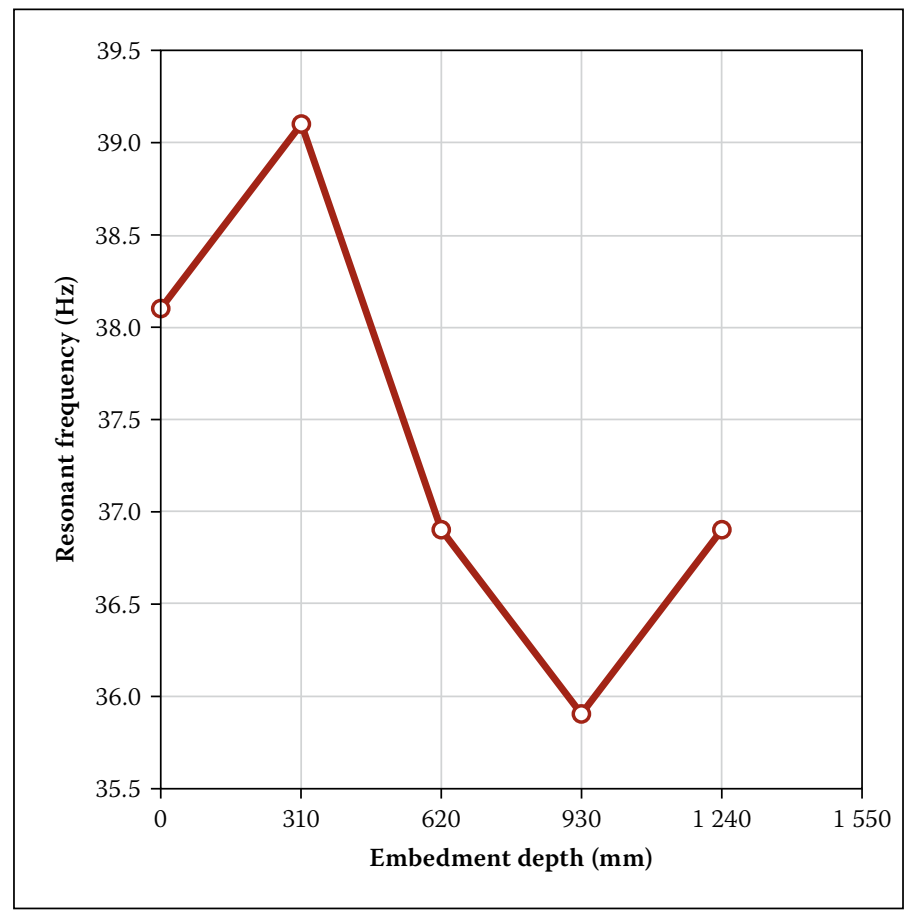

Figure 12: Resonant frequency 


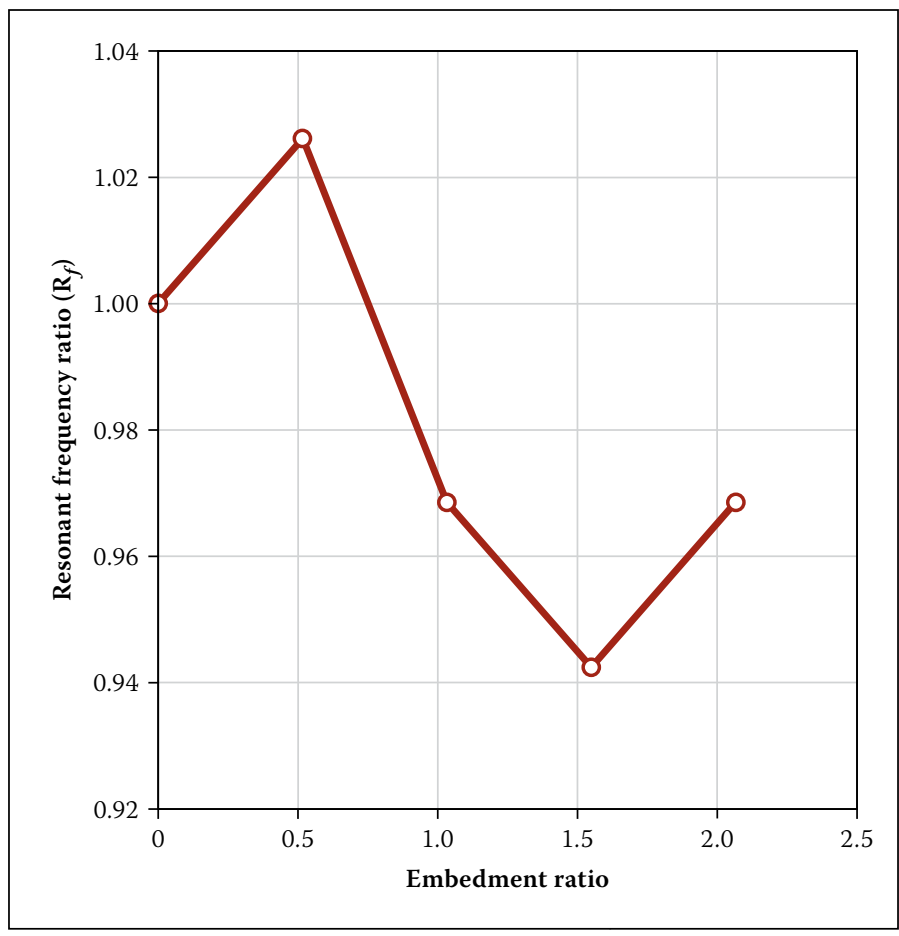

Figure 13: Resonant frequency ratio

\section{Resonant frequency}

For undamped systems, the resonant frequency is equal to the natural frequency of the foundation systems, but for a damped system, the resonant frequency is less than the natural frequency. The field-measured resonant frequency showed very slight change as the embedment increased.

Figure 12 shows the plot of the resonant frequencies against embedment depth. The resonant frequency measured in the experiment varied by about $3 \mathrm{~Hz}$, regardless of the embedment depth.

The effect of embedment on the resonant frequency of the foundation system can also

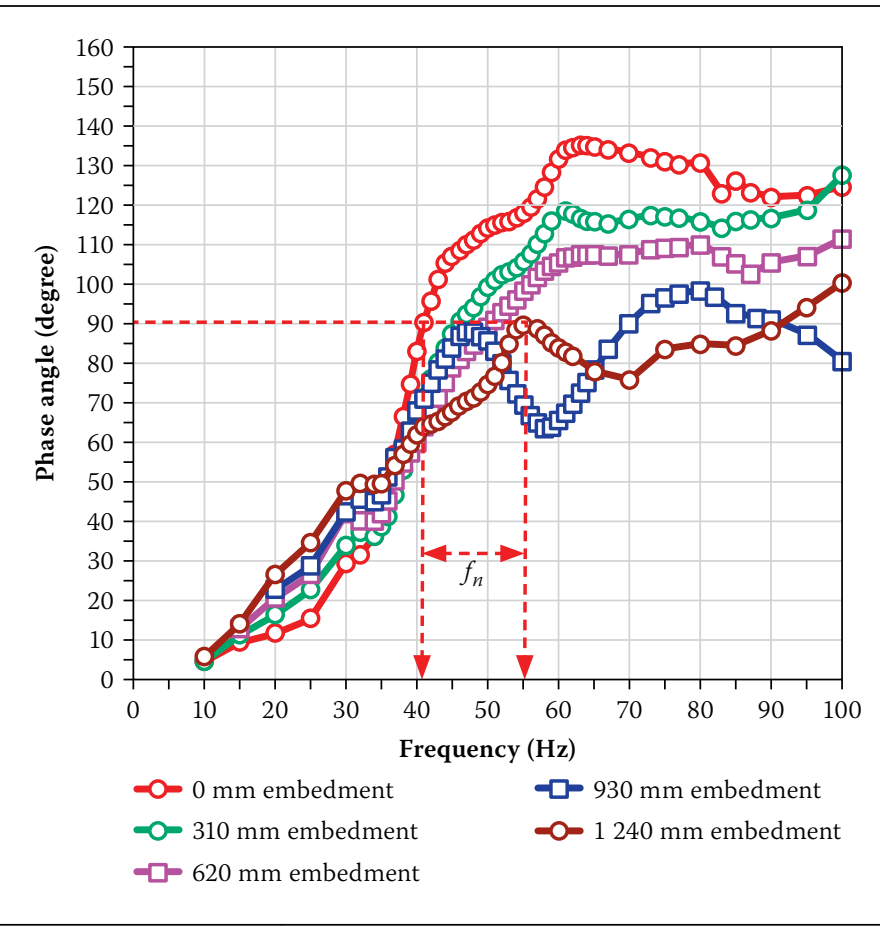

Figure 14: Natural frequency - phase angle

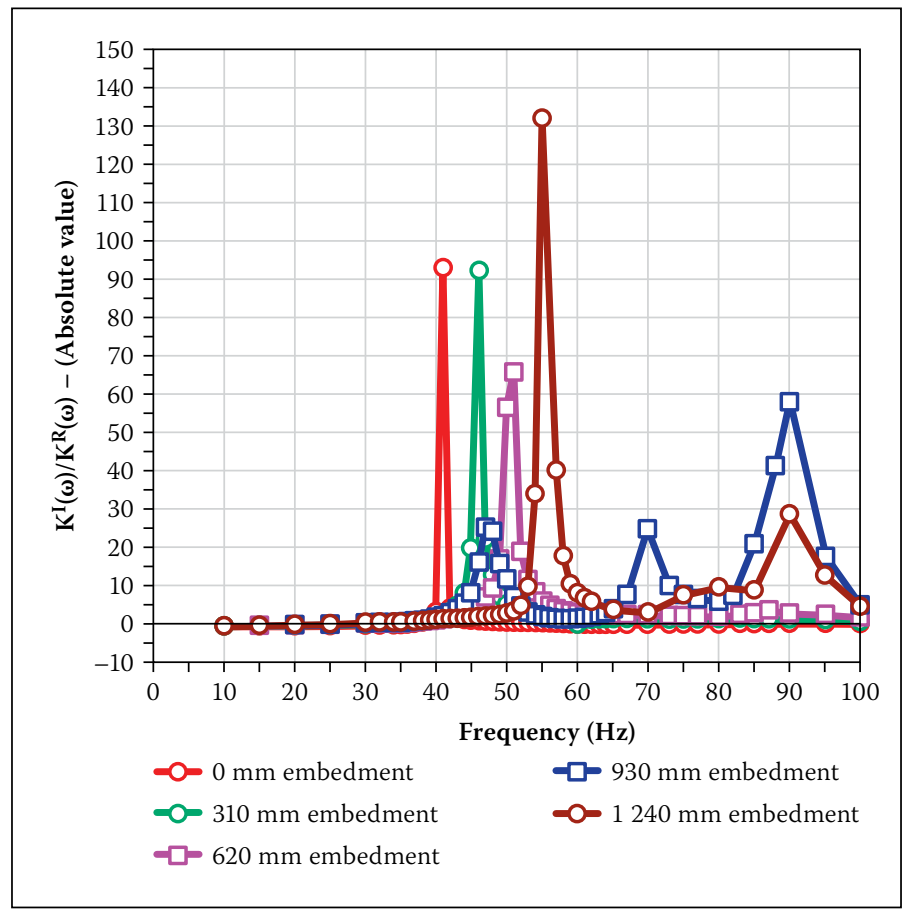

Figure 15: Natural frequency be quantified using the dimensionless parameter resonant frequency ratio (Equation 3). A plot of the resonant frequency ratio versus the embedment ratio obtained from the field measurements is shown in Figure 13. The results showed that the resonant frequency ratio was within $6 \%$ of the resonant frequency ratio at zero embedment, regardless of the level of embedment.

\section{Natural frequency}

The natural frequency of a machine foundation system can be obtained from the plot of phase angle versus forcing frequency. The phase angle is defined as the phase difference between the force vector and the displacement vector. The natural frequency is obtained by finding the frequency at which the displacement response of the foundation changes from being in phase to becoming out of phase with the forcing function.

For an undamped system this is an abrupt occurrence, as the forcing frequency passes through the natural frequency. For damped systems, such as machine foundations, this is a more gradual process, and the natural frequency is taken to be the frequency at which the phase difference between the force and amplitude vectors is 90 degrees. The experimental data shown in Figure 14

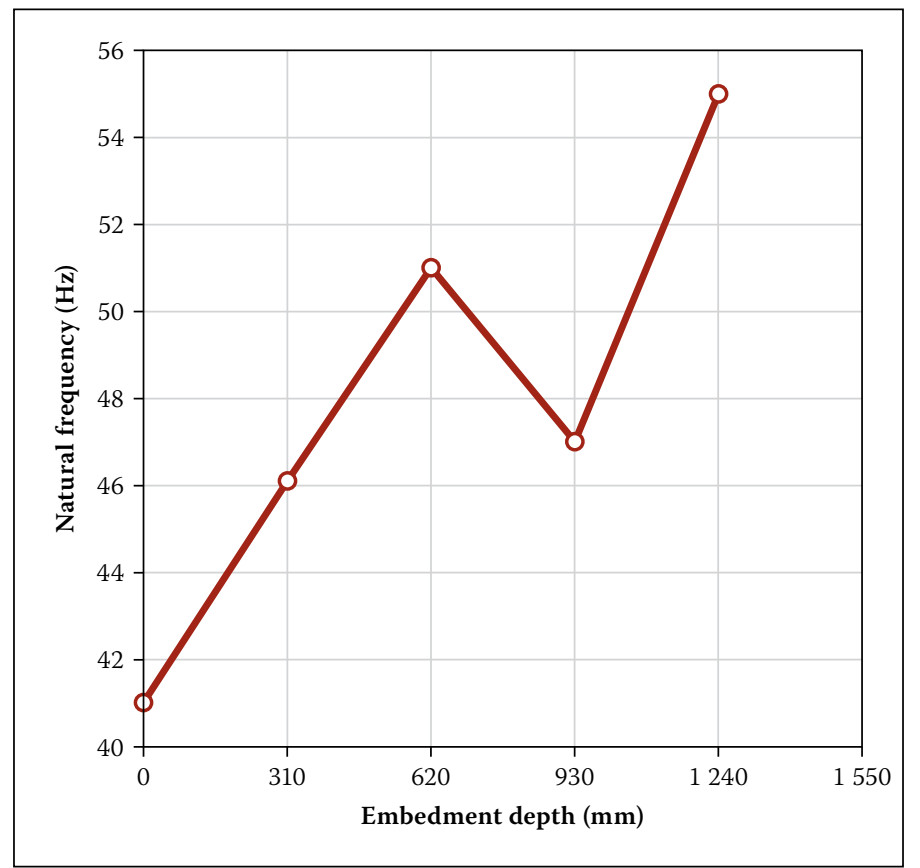

Figure 16: The effect of embedment on the natural frequency of the foundation system 


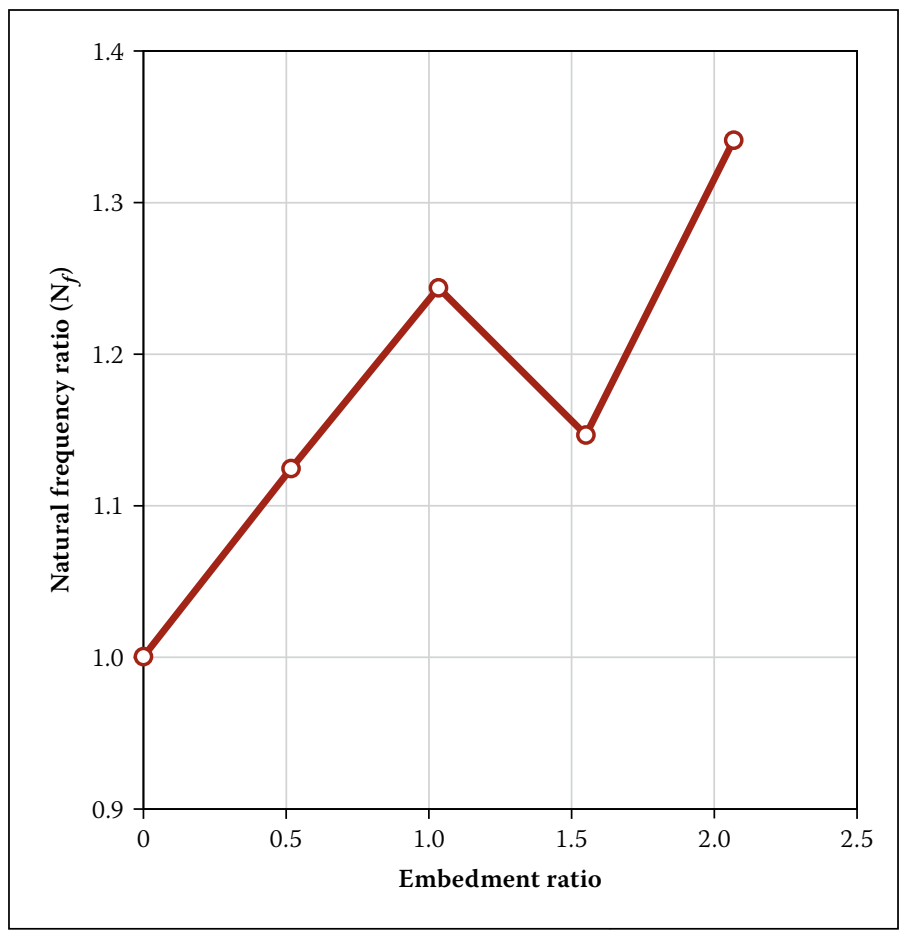

Figure 17: Natural frequency ratio for different levels of embedment

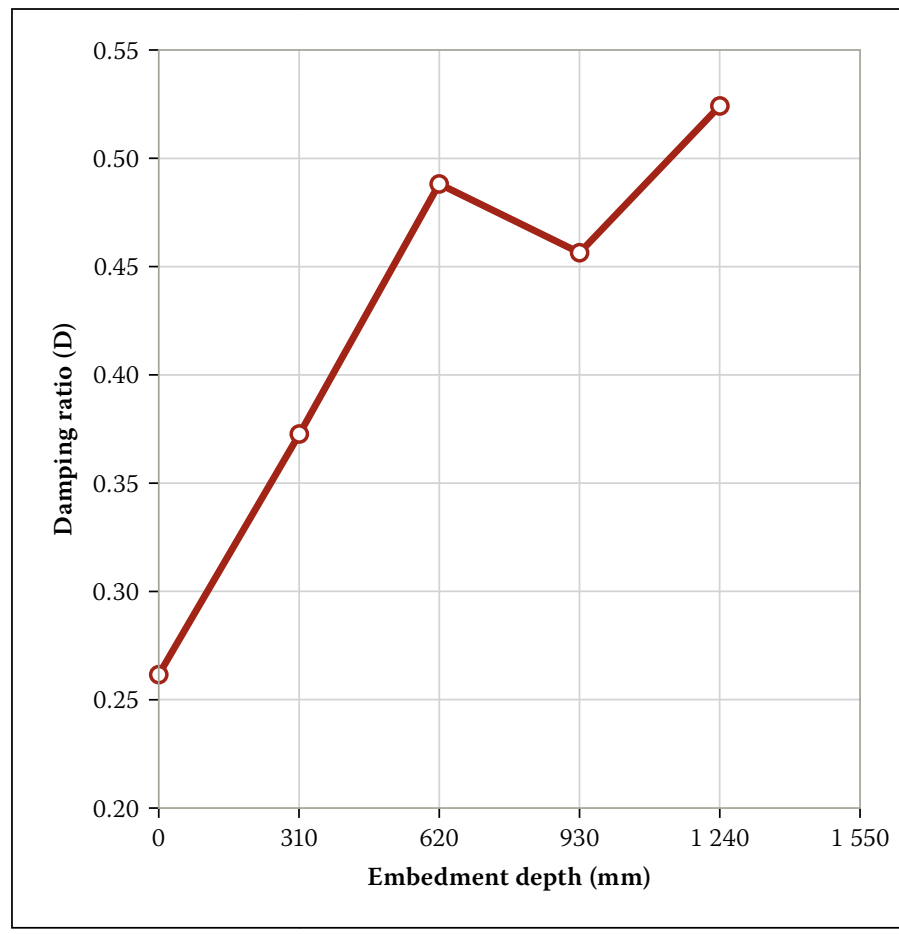

Figure 18: Damping ratio shows that, in general, the natural frequency of the foundation system increases as the embedment increases. The natural frequency increased from $41 \mathrm{~Hz}$ at zero embedment to $55 \mathrm{~Hz}$ at full embedment.

The natural frequency of the foundation system can also be obtained from a plot of loss angle versus frequency of excitation (Tileylioglu 2008). The loss angle is determined from the ratio of the imaginary part to the real part of the complex dynamic stiffness, and the natural frequency occurs at the peak loss angle. The peak occurs because the denominator (real part) is close to zero near the natural frequency, as shown in Equation 7.

$K_{o}-M \omega^{2}=0$

where $\omega$ is the angular velocity of the excitation, $K_{o}$ is equivalent to static stiffness $\left(K_{o}=K_{\text {static }}\right)$ and $M$ is the mass of the vibrating mechanism. The loss angles versus forcing frequency for the experimental data are shown in Figure 15 on page 31. The plot again shows that the natural frequency increases as the embedment increases.

Figure 16 on page 31 shows the natural frequency of the foundation system versus embedment depth. The figure shows that, in general, there is a trend of increasing the natural frequency of the foundation system as the embedment increases. The same result is shown in non-dimensional form in Figure 17 as natural frequency ratio and embedment ratio. The figure shows that the natural frequency of the foundation at full embedment was $35 \%$ higher than the natural frequency at zero embedment.

\section{Damping ratio}

The damping ratio of the foundation system may be determined from the resonant frequency and natural frequency using Equation 8:

$\omega_{r}=\omega_{o} \sqrt{1-2 D^{2}}$

Where $\omega_{r}$ is the resonant frequency, $\omega_{o}$ is the undamped natural frequency of the foundation system, and $D$ is the damping ratio of the system.

The measured damping ratios for foundation systems with different levels of embedment are shown in Figure 18. It shows that, as the embedment increases, there is a significant increase in damping ratio. The rate of increase of damping ratio is more pronounced at low values of embedment ratio, becoming less pronounced near full embedment. Nonetheless, Figure 18 shows that there is a significant advantage to embed machine foundations, as higher levels of damping produce lower vibration amplitudes.

\section{CONCLUSIONS}

During this study, the effect of embedment on the dynamic response of a foundation subjected to vertical vibration loading was investigated. A $1200 \mathrm{~mm} \times 1200 \mathrm{~mm}$ square concrete footing with a depth of $1240 \mathrm{~mm}$ was cast in the field, and the dynamic responses were measured when the footing was embedded at $0 \mathrm{~mm}, 310 \mathrm{~mm}$, $620 \mathrm{~mm}, 930 \mathrm{~mm}$ and $1240 \mathrm{~mm}$.

Different response parameters of the foundation were observed. These included the resonant and natural frequency, and the amplitude at the resonant frequency. The non-dimensional parameters of resonant amplitude ratio, resonant frequency ratio, natural frequency ratio and damping ratio were also determined. From this field study, the following was concluded:

- The resonant amplitude decreases as embedment increases. The rate of reduction of the resonant amplitude was high at low values of the embedment ratio. This suggests that even small levels of embedment can significantly reduce the maximum vibration amplitude. The results also indicate that the benefit of embedment diminishes at high embedment depths.

- The complex dynamic stiffness, including both the real and imaginary parts, increases as the embedment increases.

- The resonant frequency changes only slightly as the embedment increases, with the resonant frequency ranging within $6 \%$ at all levels of embedment.

- The natural frequency increases as the embedment increases. The natural frequency at full embedment was 35\% higher than at zero embedment.

- The damping ratio increases as the embedment increases. It was shown that the rate of increases of damping ratio is more pronounced at low levels of embedment, again confirming that even small levels of embedment can significantly improve the performance of a machine foundation system.

\section{ACKNOWLEDGEMENTS}

The authors wish to acknowledge the financial contribution made towards this project 
by Anglo Technical Division, a division of Anglo American plc, as well as THRIP (Grant number 71875).

\section{REFERENCES}

Chae, Y S 1971. Dynamic behaviour of embedded foundation-soil systems. Highway Research Record, No. 323: 49-59.

Chopra, A K 2007. Dynamics of Structures: Theory and Application to Earthquake Engineering, 3rd ed. Englewood Cliffs, NJ: Prentice-Hall.

Doebelin, E O 1998. System Dynamics: Modelling, Analysis, Simulation, Design. New York: Marcel Dekker.

Gazetas, G 1983. Analysis of machine foundation vibrations: State of the art. Soil Dynamics and Earthquake Engineering, 2(1): 1-42.

Gazetas, G M \& Stokoe, H K 1991. Free vibration of embedded foundations: Theory versus experiment. Journal of Geotechnical Engineering, 117(9): 1382-1401.

Gupta, B N 1972. Effect of foundation embedment on the dynamic behaviour of the foundation-soil system. Geotechnique, 22(1). 129-137.

Heymann, G 2007. Ground stiffness measurement by the continuous surface wave test. Journal of the South African Institution of Civil Engineering, 49(1): 25-31.

Inukai, T \& Imazawa, T 1992. Dynamic behaviour of embedded structure on hard rock site. Proceedings, 10th World Conference on Earthquake Engineering, 19-24 July, Madrid, Spain. Rotterdam: AA Balkema, $1695-1700$.

Lin, A N \& Jennings, P C 1984. Effect of embedment on foundation-soil impedances. Journal of Engineering Mechanics, 110(7): 1060-1075.

Lysmer, J \& Kuhlemeyer, R L 1969. Finite dynamic model for infinite media. Journal of the Engineering Mechanics Division, ASCE, 95(4): 859-877.
Mbawala, S J 2015. Behaviour of machine foundations subjected to vertical dynamic loading. PhD Thesis. University of Pretoria.

Novak, M 1970. Prediction of footing vibrations. Journal of the Soil Mechanics and Foundation Division, ASCE, 96(3): 837-861.

Novak, M 1974. The effect of embedment on vibration of footings and structures. Proceedings, 5th World Conference on Earthquake Engineering, 25-29 June 1973, Rome. Milan: Editrice Libraria, Vol. 1, 2658-2661.

Novak, M \& Beredugo, Y O 1972. Vertical vibration of embedded footing. Journal of the Soil Mechanics and Foundation Division, ASCE, 98(12): 1291-1310.

Novak, M, Nogami, T \& Aboul-Ella, F 1978. Dynamic soil reactions for plane strain case. Journal of the Engineering Mechanics Division, ASCE, 104: 953-959.

Tileylioglu, S 2008. Evaluation of soil-structure interaction effect from field performance. $\mathrm{PhD}$ Thesis. Los Angeles, CA: University of California. 